Marisa Mourinha*

Universidade de Lisboa - CEC

\title{
O português lá fora: algumas reflexões sobre a circulação da literatura de língua portuguesa ${ }^{1}$
}

\section{Resumo:}

A divulgação de uma obra literária depende de vários factores, mas que o público tenha acesso a ela é uma condição sine qua non, pelo que a tradução tem um papel capital neste processo. No entanto, as obras literárias com origem em sistemas periféricos têm dificuldade em chegar aos seus potenciais leitores. Sabemos que uma tradução para uma língua central pode ser uma forma para que uma obra de um sistema periférico chegue a outros de dimensão semelhante (Sapiro 2008), mas a verdade é que os sistemas centrais tendem a deixar pouco espaço para a literatura traduzida (Even-Zohar 1990). Não deve portanto surpreender-nos quando diz Casanova ser a tradução "o maior prémio e a maior arma na competição literária internacional" (Casanova 2004: 133). De que modo poderá então a literatura de língua portuguesa aspirar a um lugar de maior visibilidade? Quais os principais agentes que intervêm no processo? Este artigo procura avaliar a que canais têm acesso estes produtos culturais, e de que modo a selecção de obras e autores a serem traduzidos reflecte (ou não) um projecto e/ou uma política cultural consistentes.

Palavras-chave:

tradução, cânone, instituições, sistemas literários, circulação da literatura

\section{Abstract:}

The dissemination of a literary work depends on several factors, but its availability to the public is a sine qua non and, for that reason, translation plays a capital role in this process. However, literary works from peripheral systems will thus have particular difficulty in finding its way to their potential readers. We know that a translation into a central language may be a way for a work from a peripheral system to reach others of a similar dimension or condition (Sapiro 2008), but central systems do tend to leave little space for translated literature (Even-Zohar 1990). One should not be surprised, then, to learn that for Casanova "Translation is the major prize and weapon in international literary competition" (Casanova 2004: 133). How, in that case, can Portuguese language literature aspire to a place which could grant it more visibility? What are the main actors involved in the process? This paper tries to assess what circuits do these cultural products have access to, and how the selection of works and authors to be translated mirrors, if at all, a cultural project and/ or policy. 
Keywords:

translation, canon, institutions, literary systems, circulation of literature

\section{Introdução}

O objectivo deste estudo, como o título tenta sugerir, é proceder a um conjunto de reflexões sobre a circulação internacional da literatura e a formação do(s) cânone(s), a partir de elementos fornecidos por um estudo de caso centrado na literatura de língua portuguesa - e, especificamente, na tradução e recepção de traduções do português no estrangeiro. Partindo do princípio que, pelo menos no caso das línguas menos centrais, a tradução é um primeiro passo necessário para uma internacionalização, a intenção é discernir em que moldes se dá esse trânsito.

A nossa análise tem por base uma concepção de cultura próxima da que expõe Bourdieu (1992, 2000), cujo trabalho estabelece a ligação entre cultura e mercado: a sua noção de capital cultural, nomeadamente, poderá servir de elo dialéctico entre o cultural e o económico. Centramo-nos, porém, no pressuposto de que a literatura em tradução se comporta de acordo com um conjunto de regras que lhe é exclusivo e que não são, estritamente, nem Les règles de l'art (1992) e nem coincidem rigorosamente com os parâmetros que caracterizam a produção e circulação da literatura em geral.

Equivale isto a dizer que o quadro teórico em que nos movemos está menos próximo do da hermenêutica ou do da linguística que do dos estudos sociais. Pode-se dizer que a reflexão contemporânea sobre tradução encontra as suas raízes na hermenêutica - onde trabalhos como os de Schleiermacher ([1813] 2012) ou de Benjamin ([1923] 1969) vieram alimentar outros, como os de Ricoeur (1981) e de Derrida (1985) - é no âmbito da linguística que os Estudos de Tradução acabam por se constituir como disciplina. Partimos, pois, daquilo que ficou conhecido por Descriptive Translation Studies (Holmes [1972] 2000, Lambert e Van Gorp 1985, Toury 1995), uma escola que se afirmou a partir dos anos de 1970 e que se distingue pela ênfase colocada numa análise empírica, muito focada no contexto de chegada. Com base num eixo que liga Leuven a Tel-Aviv, esta linha aplica uma abordagem comparatista à teoria dos polissistemas, desenvolvida por Even-Zohar (1990). Sem prejuízo da atenção dada a contributos mais recentes, como é o caso do que ficou conhecido pela viragem cultural (Bassnett/Lefevere 1990), a terminologia usada neste artigo é, genericamente, a de Even-Zohar, relativa aos sistemas literários e às relações entre estes.

Para este estudo, e visto que não nos detemos tanto nos textos das traduções em si quanto na existência das mesmas e na respectiva circulação, tem pois particular relevância a escola parisiense de sociologia de literatura que, a partir de Bourdieu, se tem debruçado sobre a lógica do valor literário e da formação do cânone, nomeadamente através de trabalhos como os de Pascale Casanova (2014), sobre a circulação da literatura e as instâncias de consagração, e os de Gisèle Sapiro (2008, 2014, 2016) e Johan Heilbron (1999, 2010), mais especificamente sobre a tradução. 


\section{0 português no mundo}

Que a literatura traduzida possa ser considerada um sub-sistema no seio de um sistema mais amplo não é novidade (Even-Zohar 1990). O que se pretende aqui escrutinar são as modalidades de constituição desses sub-sistemas - ou, se assim se pode dizer, de alguns de seus segmentos. Esta reflexão nasce da convicção, sugerida pelos dados adquiridos no decorrer de um estudo de caso, de que, devido a uma confluência de factores, aquilo que acaba por ser traduzido e publicado numa dada língua não é senão uma imagem anamorfótica do cânone que lhe está na origem: por outras palavras, que aquilo que, da literatura de língua portuguesa, é traduzido e publicado no estrangeiro constitui um corpus que não corresponde a uma versão reduzida ou seleccionada do cânone dos sistemas de partida, mas a algo a que se poderia chamar um cânone alternativo, ajustado às condições culturais dos sistemas de chegada.

Comecemos por esclarecer que nos referimos a literatura em língua portuguesa e não, estritamente, à portuguesa, pela importância de que se revestem os limites linguísticos no universo da tradução: levada a cabo por especialistas que se formaram e exercem a sua actividade num sistema organizado por uma divisão em línguas, o tradutor literário é habitualmente considerado apto para um determinado trabalho em função do seu conhecimento da língua do texto de partida, apesar dos condicionalismos ditados pelos diferentes contextos culturais que partilham uma mesma língua. No caso da tradução literária, nomeadamente, poder-se-ia considerar que é frequentemente relevante a preparação extra-linguística para a compreensão não só do vocabulário num sentido mais estrito, como também de outras nuances que moldarão a interpretação do texto. Um exemplo deste fenómeno, no universo do português, é-nos dado por Daniela Ferioli, que traduziu para italiano vários livros de Jorge Amado, e que declara numa entrevista:

(...) em 1996, a Einaudi fez-me retraduzir Jorge Amado, porque as primeiras traduções tinham-no destruído. Quando tinha sido pela primeira vez traduzido e publicado em Itália, havia falta de tradutores do português brasileiro, pelo que as traduções tinham sido confiadas a tradutores de língua espanhola ou, quando muito, de português, mas que em todo o caso desconheciam a realidade e a linguagem, usos e costumes do norte [sic] do Brasil. Um autêntico desastre. O estilo dos primeiros livros, Suor, Cacau, Jubiabá, pobre, seco, e enxuto como aquelas terras, tinha-se tornado pomposo, rico, pletórico. Já para não falar nos erros, de que criei um bestiário. ${ }^{2}$ (Zornetta 2016: 419)

Naturalmente que é possível argumentar que um tradutor, para dizer-se competente numa língua, teria de dominar as suas variantes, como (segundo os seus testemunhos) é o caso de Gregory Rabassa (2005: 72, 145). Mesmo assim, as críticas dirigidas por esta tradutora aos seus predecessores contemplam não só questões que se poderiam atribuir ao desconhecimento do território ou da especificidade da sua tradição linguística, mas também a uma falta de sensibilidade estilística que pode, em nosso entender, ser reconduzida à deficiente formação em matéria literária. 
No entanto, a praxis é que tanto os departamentos das universidades quanto as escolas de línguas tomam em conta preponderantemente a divisão linguística; e mesmo em ambientes onde se dá destaque às literaturas e ao respectivo enquadramento histórico e cultural, é frequente, devido à estrutura e à filosofia subjacentes às instituições universitárias, com o enfoque na especialização, que a formação não seja transversal, antes incida desigualmente sobre os vários aspectos passíveis de serem reconduzidos a uma mesma disciplina linguística: desta forma, torna-se possível que um licenciado em alemão saiba pouco ou nada sobre literatura suíça de língua alemã ou sobre um ou vários períodos das tradições literárias escritas em alemão; como sucede que haja especialistas em português que ignoram a literatura brasileira contemporânea, ou a portuguesa quinhentista, ou a angolana etc, conforme se cruzem, no seu percurso lectivo, com especialistas de uma ou de outra coisa. Esta nota sobre o funcionamento das instituições universitárias será relevante para a nossa argumentação, dada a importância da academia na tradução de línguas periféricas como o português.

Tomando, pois, como unidade de análise a literatura escrita em português, é preciso dizer que se trata de uma língua periférica e que tem, como tal, e por definição, uma circulação restrita. Por este motivo, a tradução de uma obra destas literaturas para uma língua estrangeira é vista como uma vitória - vitória que é tanto maior quanto maior for o prestígio do sistema de chegada. Diz Casanova (2004: 133) que a tradução é "o maior prémio e a maior arma na competição literária mundial". Fala pois de competição. Sapiro (2014) retomará esta ideia ao escrever sobre a tradução como arma. Apter fala em guerra: "The translation zone is a war zone" (Apter 2011: XII). Vejamos as palavras de Casanova:

Translation is the foremost example of a particular type of consecration in the literary world. Its true nature as a form of literary recognition (...) goes unrecognized on account of its apparent neutrality. Nonetheless, it constitutes the principal means of access to the literary world for all writers outside the center. Translation is the major prize and weapon in international literary competition, an instrument whose purpose differ depending on the position of the translator with respect to the text translated that is, on the relation between what are commonly called "source" and "target" languages. (Casanova 2004: 133)

Estamos, portanto, perante um ambiente pautado pelos conflitos e pelas assimetrias de poder. E, neste âmbito, o facto é que mesmo quando uma obra das literaturas de língua portuguesa chega a aceder a um contexto internacional através de uma tradução, essa tradução mais não faz que colocá-la num ambiente onde o equilíbrio de forças lhe é desfavorável, quando não mesmo hostil. Uma literatura periférica tem sempre dificuldade em sair das suas fronteiras; se existe sempre a hipótese de a obra em questão ser traduzida para uma língua central, aumentando assim a probabilidade de chegar a outros sistemas periféricos, a natural resistência dos sistemas centrais à literatura traduzida torna esta possibilidade muito reduzida. Que possibilidades têm então estas literaturas de se internacionalizar, de exportar aquilo que é, nos respectivos sistemas, considerado canónico? 


\section{Tradução e cânone}

Lefevere (1992) refere-se à tradução em termos de reescrita e manipulação. No entanto, para ele, a tradução num sentido estrito não é o único mecanismo que leva a cabo uma reescrita: a antologia é também um exemplo de reescrita. Lefevere explica como as antologias contribuem para construir e/ou fixar um cânone, sobretudo, mas não só, em ambientes de matriz ou de vocação didáctica. É possível pensar o conjunto das traduções de um determinado sistema, no seio de outro, como um processo de antologização.

Seleccionar, numa acepção positiva, consiste em identificar a excelência. Mas seleccionar é também, necessariamente, excluir. Daqui resulta que, se o conjunto de obras traduzidas para uma determinada língua pode considerar-se uma forma de selecção ou antologização, é preciso ter em conta não só o que este mecanismo inclui mas também tudo aquilo que descarta - e analisar as razões por detrás destas omissões. Recordemos, seguindo Toury, que as opções que ditam aquilo que é preterido e aquilo que é incluído nessa putativa antologia de traduções têm muito menos a ver com o sistema que as produziu do que com o sistema que se as recebe: a tradução é um facto da cultura de chegada (Cf. Toury 1995: 24).

O nosso trabalho de investigação tem-se focado, nos últimos anos, sobretudo nos sistemas de língua italiana e inglesa e especificamente no que concerne à circulação da literatura de língua portuguesa. No âmbito dessa investigação tem-se verificado que, nomeadamente no caso da literatura de língua portuguesa, se produz um efeito curioso que consiste numa espécie de deslocação do cânone: não só aquilo que acaba por ser publicado no estrangeiro não coincide exactamente com o que, no sistema de origem, é considerado canónico; dá-se também o caso de que os mesmos textos, quando sucede que são publicados fora do seu sistema de origem, têm uma recepção diferente - e, por vezes substancialmente diferente.

Longe de ser uma novidade, este tipo de assimetrias corresponde, justamente, ao diagnosticado pela escola dos Descriptive Translation Studies, como nos recordam Helgesson e Vermeulen (2016: 9). Não se trata, pois, de uma excepção que seria válida só para um case study: o facto é que os mecanismos que governam a tradução não são exactamente os mesmos que regem a consagração. Mediação há sempre, mas a tradução implica um trabalho de mediação especializado e que não é só linguístico. Mais do que verter um texto numa outra língua, está em causa comunicar uma poética (Cf. Lefevere 1992) num sistema que lhe é alheio. Como é comunicado o produto cultural (o livro, o autor) é um factor de uma importância capital numa eventual internacionalização - a forma como essa mediação tem efectivamente lugar, porém, depende dos canais usados e dos agentes envolvidos.

Sendo um produto com características próprias, na medida em que é um bem cultural, mesmo assim um livro é certamente um produto; e, para que chegue ao seu público, tem que passar por um mercado editorial - que tem as suas regras específicas, mas é um mercado, com tudo o que isso implica. O mercado da tradução, contudo, é um segmento à parte nesse universo, e tem um comportamento distinto, num ambiente já de si peculiar.

O mercado do livro funciona de acordo com dois paradigmas: para usar a terminologia de Bourdieu (2000), o do circuito de grande circulação, dito comercial, onde as leis são grosso modo 
as do mercado; e um outro circuito de circulação restrita, onde o que conta é sobretudo o capital cultural, que deriva do valor estético ou intelectual do produto. Estes universos não são estanques: as duas categorias convivem e, por vezes, sobrepõem-se. ${ }^{3}$

De resto, esse mesmo paradoxo constitui um dos traços que definem o mercado de bens simbólicos: uma editora investe num determinado autor (ou literatura ou linha editorial) pelo seu valor estético, com vista a um retorno que não é imediatamente material. o primeiro efeito é de prestígio. Mas esse valor simbólico, a seu tempo (pelo menos idealmente) converte-se em vendas e em lucro material. A perversidade do sistema actual, que tende para o monopólio, que se coloca não só a nível da edição quanto da distribuição, é que os editores do grande circuito têm hoje um poder tal que acabam por se apropriar destes produtos de prestígio quando eles se tornam passíveis de uma circulação de massa. ${ }^{4}$

Estes dois circuitos movem-se de forma diferente, os agentes e os factores que intervêm não são os mesmos, e a literatura circula de forma distinta num e no outro. Para as literaturas periféricas, é mais difícil o acesso ao grande circuito: nos sistemas centrais a tradução é, por definição, minoritária; portanto, é também relegada para as franjas do sistema. Nos sistemas menos centrais é certo que há mais tradução, mas a grande fatia é sempre ocupada pelas línguas com mais poder que o português.

Como consequência, um autor que ocupa uma posição canónica no seu sistema de partida, como Machado de Assis ou Eça de Queiroz, não chega necessariamente a ter uma carreira internacional, por um lado; e, por outro, mesmo que a tenha, dificilmente terá um estatuto paralelo nos vários sistemas de chegada onde venha a ter presença. No caso destes dois autores, Machado parece estar a atravessar um bom momento, com uma recente tradução para italiano ${ }^{5}$ das $\mathrm{Me}$ mórias Póstumas de Brás Cubas, e nada menos que duas novas traduções para inglês, a juntar às já existentes. Eça, por seu turno, que já foi bastante visível em Itália em décadas passadas, está hoje virtualmente ausente desse mercado (Cf. Russo 2007), apesar de continuar a merecer a atenção de tradutores e editores de língua inglesa, com várias chancelas a editarem consistentemente ao longo das últimas décadas traduções de obras suas.

\section{Tradução e ideologia}

Falando de tradução, Lefevere fala, entre outras coisas, em ideologia, poética e poder:

Translation is, of course, a rewriting of an original text. All rewritings, whatever their intention, reflect a certain ideology and a poetics and as such manipulate literature to function in a given society in a given way. Rewriting is manipulation, undertaken in the service of power (Lefevere 1992: vii)

A resposta à questão sobre quais são os factores e os agentes que intervêm na divulgação da literatura a nível internacional passa portanto por discernir o seguinte: quem traduz e com que finalidade.

No sistema italiano, em particular, o meio académico tem muito peso e muita influência na selecção das traduções e sobretudo no que diz respeito às traduções de línguas periféricas 
como é o caso do português: praticamente não existe o tradutor profissional, quase sempre o tradutor de português em Itália é um académico. A grande excepção é Rita Desti, tradutora de Saramago, entre outros, e publicada por grandes chancelas editoriais, como a Einaudi ou a Feltrinelli. Entre os tradutores de português que publicam com estas grandes editoras, estão hoje no activo sobretudo Roberto Francavilla (tradutor de Chico Buarque ou Clarice Lispector), que ensina na Universidade de Génova, e Vittoria Martinetto (tradutora de Lobo Antunes), que ensina na Universidade de Turim.

Na lista dos tradutores do português em Itália, raros são os que não têm, de uma forma ou de outra, uma ligação à academia; este fenómeno inclui tanto o tradutor estreante, cujo trabalho de tradução é feito como parte integrante do seu percurso formativo, quanto o do docente/ tradutor. À parte os casos (mais raros) em que o autor de língua portuguesa acede a uma das grandes chancelas, o que vemos é uma grande dispersão por editoras menores. Nesse circuito, muitas vezes a tradução é proposta ao editor pelo próprio tradutor, estreante ou experiente, de acordo com os seus interesses pessoais e de carreira. Um resultado disso é que a tradução, num contexto deste género, tem tendência para ser mais estrangeirizante (Cf. Venuti 1995, 1998) do que permitiria o circuito mais comercial.

Visto que para o académico o fundamental é publicar, e não tanto ser distribuído ou ter uma presença significativa no mercado, este modelo contribui para aumentar o efeito que alia o autor periférico à editora periférica. Muito frequentemente, trata-se de editoras não só pequenas (o que não é mau em si, do ponto de vista da divulgação, no sentido em que pode produzir o efeito de culto, ou de nicho) mas também pouco especializadas, frequentemente com pouca consciência do que publicam, e do valor literário, ou da posição do que publicam nos respectivos cânones de origem. Um exemplo disto foi a sorte editorial do angolano Pepetela, cujas obras foram, em Itália, até agora publicadas em pelo menos 9 editoras diferentes, todas de pequena dimensão, sendo que só uma delas (Edizioni del Lavoro) editaram mais que um volume deste autor.

Uma consequência muito directa do envolvimento da academia na criação de um corpus de literatura traduzida numa dada língua é este deslocamento do cânone de que falávamos, e que depende dos critérios por detrás das escolhas. Naturalmente que, no grande circuito comercial, as escolhas tendem para recair sobre autores e obras que tenham boas hipóteses de vingar no mercado. Desse ponto de vista, autores vivos são preferíveis, pela possibilidade de circularem pelas feiras e festivais internacionais: a exploração da imagem do autor é um poderoso instrumento de marketing editorial na actualidade.

Mas, nos circuitos restritos onde têm mais hipótese de circular os autores de sistemas periféricos, estes critérios têm menos expressão. $O$ editor que aposta na escolha de um académico fá-lo pelo prestígio intelectual ou estético de produtos que sabe serem de nicho, e contando, quando muito, com as vendas motivadas pelas bibliografias das cadeiras universitárias dos mesmos docentes. Resultado deste processo é que abre maior espaço para a idiossincrasia: chegam à publicação no estrangeiro as obras que forem traduzidas por ou sob a orientação de um número muito restrito de agentes culturais; quando se trata de docentes universitários, as suas escolhas recaem sobre os seus interesses de pesquisa e de carreira, quando não simples- 
Cadernos de Literatura Comparada

O português lá fora: algumas reflexões

mente do seu gosto pessoal.

É assim que temos, em Itália, publicados pela editora La Nuova Frontiera, uma pequena editora que goza de algum prestígio, o popular angolano José Eduardo Agualusa lado a lado com a moçambicana, quase desconhecida do público, Paulina Chiziane. Chiziane, de resto, constitui um caso emblemático desta deslocação do cânone: uma das poucas mulheres negras nos países africanos de língua portuguesa a ganhar nome como romancista, tem vindo a ser recorrentemente seleccionada para publicação no estrangeiro, onde tem um destaque que contrasta com a recepção tanto no seu país quanto em outros países de língua portuguesa - no sentido em que, ao contrário de muitos outros autores mais consagrados e/ou populares, acaba por ser quer estudada pela academia, quer traduzida e editada fora do espaço de língua portuguesa (Cf. Bucaioni 2017, 2020).

\section{Os agentes da tradução}

Isto é o que acontece no sistema italiano, mas é também o que acontece em muitos outros sistemas. E embora haja, obviamente, diferenças no estatuto que a literatura portuguesa tem junto dos vários contextos, há traços comuns: os sistemas centrais têm sempre pouco espaço, em absoluto, para o que vem de fora, e os sistemas periféricos traduzem muito mas sobretudo das línguas mais centrais, pelo que o efeito acaba por ser semelhante.

Estas afirmações são confirmadas pelos trabalhos de Mulinacci (2015) sobre as relações entre Brasil e Itália, Guerini et alii (2008) sobre o Brasil no mundo, Bucaioni (2017, 2020) sobre a recepção dos africanos de língua portuguesa, Wilczek (2012) sobre a exportação do cânone polaco - ou ainda, mais famosamente, pelo trabalho de Venuti (2005) sobre o japonês nos Estados Unidos - mas também por causa das conclusões a que temos chegado na análise do sistema de língua inglesa (Mourinha 2020). Estudar a internacionalização não é estudar o contexto anglófono, mas este contexto desempenha seguramente um papel preponderante.

Escreve Wilczek no âmbito de um estudo que faz sobre a divulgação da literatura polaca:

Thus we have here the four necessary elements that I claim make it possible for a work of literature from outside the English-speaking world to become a part of the canon: a good translation into English made by an already well-established translator; a well-known publisher (...); a recommendation from a critic who belongs to influential literary circles (...); and an enthusiastic review in a major literary journal or magazine (...). (Wilczek 2012: 1687)

Wilczek está, neste excerto, a tentar identificar os mecanismos da reescrita (pois de reescrita se trata) que irão contribuir de forma decisiva para a recepção de uma dada obra ao ser apresentada num novo ambiente literário e cultural. Na opinião deste autor, o acesso ao cânone faz-se através do inglês: implica necessariamente não só a tradução, mas a tradução para a língua hegemónica. Nós diríamos que para uma obra de um sistema periférico pode bastar, pelo menos como primeiro passo, uma tradução para uma língua central, cujo poder não é de desprezar; para exemplificar o poder que ainda tem o sistema francês, basta recordar o 
fenómeno recente em torno do romance Stoner, de John Williams: publicado inicialmente em 1965, esteve muitos anos fora de circulação; começou depois a ser republicado, a partir do fim dos anos 1990, mas o momento decisivo parece dar-se com a tradução francesa, de resto assinada por uma tradutora "consagrante" (Cf. Casanova 2004: 135), que sai em 2011; no ano seguinte, Stoner era o livro do ano na cadeia de livrarias Waterstones, facto que veio aumentar ulteriormente as vendas.

Wilczek, usando categorias de análise onde ressoam as que propunha Lefevere, cita como agentes envolvidos neste fenómeno de tradução e canonização os seguintes: tradutores, editores e críticos literários. Seria de notar a omissão do agente literário, o que não nos parece nem casual nem despropositado. Dizia-se acima que há dois paradigmas que caracterizam a circulação de bens culturais. No circuito de grande escala, desempenham um papel fundamental os agentes literários e toda a máquina do marketing e dos grandes circuitos editoriais, incluindo as livrarias, sobretudo as grandes livrarias. Nesse contexto, o natural é que o autor de língua portuguesa chegue a Split, a Eindhoven, ou a Praga, passando por Paris, Nova Iorque, ou Frankfurt, grandes sedes de trânsito cultural - no caso de Frankfurt, especificamente literário, através da sua feira do livro para profissionais do sector.

Mas o autor que escreve em português, como o que escreve em polaco, dificilmente se moverá, à partida, nesse circuito. Resta-lhe, por isso, o circuito de pequena circulação, onde os principais agentes são, efectivamente, outros escritores, os próprios tradutores (o tradutor scout), os pequenos editores, mais especializados, e outros actores de um meio cultural que não pode senão ser restrito e restritivo porque a sua força vem desse carácter de exclusividade. Como resultado, o peso relativo de cada um dos agentes é maior. Estes agentes influem de forma determinante não só na escolha de textos, como na forma como são quer traduzidos quer apresentados ao público - e isto, independentemente de serem eles próprios tradutores. Fala-se aqui de personalidades e instituições que gozam de um prestígio que lhes permite influenciar comportamentos no sector da cultura. Trata-se de personagens como Bernard Pivot em França, Antonio Tabucchi na Itália ou Giuliano Ferrara no mesmo país. A consagração tout court funciona um pouco da mesma forma, mas a consagração fora de portas requer um outro grau de patrocínio intelectual - como se o público exigisse mais garantias antes de decidir investir (e de investir emotiva, até mais que financeiramente) num autor que vem de fora, de um meio estrangeiro.

Por vezes, são os próprios tradutores, enquanto agentes culturais, a proporem com força um autor e a liderarem o processo de divulgação: foi o caso da tradutora francesa de Miguel Torga, Claire Cayron, uma das grandes responsáveis pela carreira internacional do autor. Ou de Thomas Colchie, no arrancar da carreira internacional de Lobo Antunes (e, mais tarde, George Steiner ou Ariel Dorfman). As motivações destes agentes culturais raramente são económicas: usam a sua posição para manifestar publicamente as suas preferências, com um entusiasmo que se pode tornar contagiante. E é dessa forma que subsiste, à margem do grande circuito, uma indústria cultural em função do capital simbólico. 
Cadernos de Literatura Comparada

O português lá fora: algumas reflexões

Em certos contextos, é muito comum que os tradutores literários trabalhem gratuitamente ou em troca de uma remuneração simbólica: Sapiro (2014: 35) nomeia como exemplos categorias tão vastas como Europa de Leste, América Latina e Ásia. Para as línguas periféricas, passa-se o mesmo também em sistemas semi-centrais, como o do italiano, em que a tradução literária do português é, o mais das vezes, realizada por académicos ou pelos seus discípulos, ou para fazerem currículo ou por terem interesse em ver divulgado determinado autor. Pelo que pudemos apurar, a realidade nos Estados Unidos não é muito diferente, e a remuneração material é a última das motivações para o tradutor literário (Rabassa 1974: 37-38, Landers 2001: 6).

Exemplos deste fenómeno, no contexto italiano, são os da colaboração, nos anos de 1980, da lusitanista Giulia Lanciani (que ensinava na Universidade de Roma Tre) com a Japadre, uma pequena editora com sede em Aquila, de que resultou uma colecção em que figuravam grandes nomes da literatura portuguesa contemporânea, como Fernando Namora, Teixeira de Pascoaes, ou Sophia de Mello Breyner; ou, mais recentemente, da sinergia entre Giorgio De Marchis (também ele docente em Roma Tre) e La Nuova Frontiera de Roma, que, enquanto durou, levou à publicação de vários autores de língua portuguesa - dos quais alguns africanos, como referido acima - traduzidos quer por ele próprio quer por outros lusitanistas. Uma dinâmica semelhante pode observar-se na relação entre a editora Diabasis, de Parma, e a cátedra de português da Universidade de Bolonha, de cuja colaboração nasceram traduções de Eça e Pessoa, mas também de nomes menos expectáveis, como Hélder Macedo ou Eduardo Lourenço.

Finalmente, para culminar o quadro da colocação de traduções de português em Itália, falta fazer referência às editoras parcial ou totalmente dedicadas à lusofonia, que são hoje três, todas elas fundadas por jovens lusitanistas: as Edizioni Dell'Urogallo, de Perugia - que, desde 2009, publicaram mais de 60 traduções do português, incluindo nomes como Rubem Fonseca, José Eduardo Agualusa ou Lídia Jorge; a Vittoria Iguazú Editora, cuja actividade iniciou em 2012, com traduções de Manuel Ferreira e Álvaro do Carvalhal; e a Tuga Edizioni, cuja colecção Torre de Belém é dedicada à literatura lusófona. Destas, só as Edizioni Dell'Urogallo se dedicam exclusivamente à língua portuguesa (Cf. Ricci 2020).

Em França, tem dado uma atenção constante e cuidada aos autores de língua portuguesa, de Machado de Assis a Lídia Jorge, a editora independente Métaillé. Fundada em 1970 por Anne-Marie Métaillé, a casa começou por estar orientada para as ciências sociais que constituem a formação da fundadora, antes de se voltarem para a literatura estrangeira. Foi, porém, a entrada no sistema de distribuição das Editions du Seuil (aliada ao inopinado sucesso do então desconhecido Luis Sepúlveda), que permitiu que esta pequena editora alcançasse a presença no mercado que lhe garantiu a estabilidade necessária para o trabalho pelo qual é hoje conhecida - e foi assim que a empresa, fundada com um capital inicial correspondente ao da produção de três títulos, chegou a ter um catálogo com mais de mil.

No Reino Unido, a Carcanet Press teve uma actividade importante, no que diz respeito à divulgação de obras de língua portuguesa. Fundada em 1969 por Michael Schmidt, começou por ser especializada em poesia, mas acabou diversificar a sua actividade à medida que foi crescendo. Em 2000, foi nomeada pelo Sunday Times "Small Publisher of the Year". Com 
quatro vencedores de prémios Nobel entre os seus autores, para além de vários Pulitzer e outros prémios de prestígio, a Carcanet é o perfeito exemplo de pequeno editor de excelência. Embora, em anos mais recentes, pareça ter esmorecido a sua actividade de tradução do português, esta editora conta, na colecção Aspects of Portugal, com vários títulos de Eça de Queiroz e de Miguel Torga, além de outros sobre Portugal e os portugueses.

O contexto britânico funciona de forma distinta, relativamente ao Americano (Cf. West III 2012) onde, como vimos pelos testemunhos de Rabassa e Landers citados acima - ambos tradutores de António Lobo Antunes, e ambos ligados à academia - a tradução literária não é um mester que proporcione grandes rendimentos. A parábola da presença de Lobo Antunes no mercado norte-americano é, de resto, ilustrativa do modo como estão a evoluir as tendências. Descoberto pelo agente Thomas Colchie, que o propôs ao gigante editorial Random House, numa altura em que pouquíssimos eram os autores traduzidos naquela editora (e, ainda mais, traduzidos do português), Lobo Antunes viu uma das suas primeiras obras (Os Cus de Judas, que saíra em Portugal em 1979) ser publicada em 1983 no grande circuito editorial dos Estados Unidos. A tradutora, Elisabeth Lowe, era uma académica. A máquina publicitária de uma editora desta dimensão não é de desprezar: basta recordar que, ainda antes que a tradução do romance viesse a público, um excerto do mesmo foi publicado na prestigiada revista Granta. Uma vez publicado, tanto este como os romances seguintes foram objecto de recensão (o mais das vezes muito positiva) em jornais de referência. Mas essa carreira internacional que começou na Random House passou por muitas fases, desde 1983. Depois de várias traduções na Grove Press (editora importante e prestigiada, mas não da dimensão da Random House), assinadas tanto por Rabassa quanto pelo britânico Richard Zenith, sai em 2008 uma tradução na Dalkey Archive Press. À primeira, de Clifford Landers, seguiram-se outras, por Rhett McNeil, também ele um académico.

Mesmo que consideremos uma excepção a tradução de Jeff Love publicada, em 2019, na Yale University Press, e que representa o culminar de um percurso de deslocamento do grande para o pequeno circuito, o facto é que já a presença de um autor da dimensão de Lobo Antunes numa editora como a Dalkey Archive é extremamente significativa: trata-se de uma editora absolutamente não comercial. Fundada em Chicago nos anos de 1980, opera agora em Champaign, trabalhando muito de perto com a Universidade do Illinois. O seu compromisso com a divulgação de literatura menos convencional, e a preocupação de manter todo o catálogo disponível (in print) coloca esta chancela nos antípodas da Random House, encarnando a definição de Bourdieu de distribuição de pequena escala. Acrescente-se que as suas traduções de Lobo Antunes foram, pelo menos parcialmente, apoiadas por fundos públicos tanto nacionais como estrangeiros, testemunhando de que modo este tipo de patrocínio é relevante, mesmo na divulgação de autores já consagrados.

\section{Mecanismos de resistência}

Se, por um lado, as literaturas periféricas têm as suas desvantagens, por outro lado podem contar com estes soldados nas suas fileiras. Havendo menos actores envolvidos no processo, cada 
Cadernos de Literatura Comparada

O português lá fora: algumas reflexões

um deles tem mais peso, relativamente aos que se movem no circuito da grande distribuição.

É certo que a república mundial das letras tem as suas assimetrias de poder, mas há também factores de resistência. Há por exemplo instituições, tanto públicas como privadas, que contribuem, não só mas também financeiramente, para manter a diversidade: a nível internacional, a UNESCO tem feito muito para fomentar a diversidade cultural, não só mas também no âmbito da tradução, através de uma "política mundial do livro" que combate as assimetrias; em França, o Centre National du Livre apoia financeiramente não só traduções do francês no estrangeiro, mas também traduções para francês (e desde que o faz a percentagem de livros traduzidos em França subiu significativamente); num contexto, como o de língua inglesa, particularmente refractário a traduções, os National Endowments for the Humanities and for the Arts nos Estados Unidos e o Arts Council no Reino Unido possibilitam financiamento para projectos de tradução - e não esqueçamos que o prestigiado Man Booker Prize mudou recentemente as regras de forma a premiar também o tradutor (e em partes iguais).

Em Portugal, várias são as instituições que têm tido um papel na difusão dos autores portugueses no estrangeiro. A Fundação Calouste Gulbenkian possibilitou, através da atribuição de bolsas, a presença no território português de investigadores estrangeiros cujo objecto de estudo fosse a cultura portuguesa. A nível governamental, tem havido uma política de língua consistente, que operava, até há muito pouco tempo, sobretudo através de dois canais: por um lado, o Instituto Camões, ${ }^{8}$ que depende do Ministério dos Negócios Estrangeiros; por outro lado, aquela que é agora a Direcção-Geral do Livros, dos Arquivos e das Bibliotecas (herdeira do Instituto Português do Livro e das Bibliotecas ${ }^{9}$ ), que depende do Ministério da Cultura. Este ano, os programas de apoio à publicação de autores portugueses no estrangeiro destes dois organismos foram, pela primeira vez, feitos convergir num só programa. Até então, estes organismos tinham cada um o seu edital e têm apoiado não só a tradução de autores portugueses mas também autores dos países africanos de expressão portuguesa e de Timor-Leste. No caso do Instituto Camões, a par da actividade de patrocínio cultural com que apoia financeiramente estas traduções, tem também um outro papel fundamental, ao garantir canais de ensino da língua no estrangeiro.

Um papel semelhante começou a ser preenchido mais recentemente pela Fundação da Biblioteca Nacional do Brasil: o seu programa de apoio à tradução e publicação de autores brasileiros, que existia desde 1991, foi reformulado em 2011 com uma expressiva dotação orçamental, que lhe permitiu maior visibilidade e alcance. Desse ponto de vista, veio complementar o trabalho desenvolvido da parte das autoridades portuguesas, para cujos apoios eram elegíveis autores portugueses e africanos de língua portuguesa, mas não brasileiros. Embora recente e, até agora, numa escala menor, é ainda de destacar o esforço do governo brasileiro, através do seu Ministério das Relações Exteriores, no sentido de formar e colocar docentes de português no estrangeiro.

A relevância de iniciativas deste tipo justifica-se na medida em que uma das dificuldades das línguas periféricas é a questão muito prática da existência ou não de tradutores a quem confiar as traduções. E, apesar de todos os esforços, há grandes vazios: até há muito pouco tempo, 
em Itália, traduzia do português quem soubesse espanhol (Tocco e Lupetti 2010: 26). Maria Papadima, tradutora de Fernando Pessoa para grego, faz parte do departamento de francês da sua universidade: na falta de estruturas institucionais dedicadas, aprendeu português por conta própria.

Uma questão que se prende de forma próxima com esta é a do papel das instituições universitárias na construção dos cânones: um primeiro passo será sem dúvida o da presença de oferta didáctica - o que, para as línguas periféricas, é tudo menos garantido. Porém, resolvida esta dificuldade, há outras que se colocam, como as que derivam da gestão de forças entre línguas e disciplinas percebidas como não centrais: assim, as línguas periféricas encontram-se na circunstância de combater a hegemonia e o poder das línguas centrais, mas também a disputar entre si as preferências dos agentes culturais em formação.

\section{Considerações finais}

Para responder à pergunta inicialmente formulada sobre os canais a que terão acesso as literaturas de língua portuguesa para a sua internacionalização, diríamos que, face aos condicionamentos impostos pelo funcionamento dos mercados, e apesar da posição desfavorável que ocupa no sistema cultural mundial, a literatura escrita em português pode recorrer a mecanismos que lhe permitam apresentar o seu cânone junto de outros contextos: quer beneficiando de factores exógenos, como os programas internacionais que têm por finalidade proteger a diversidade cultural; quer, a partir de dentro, sobretudo mediante a implementação eficaz de políticas de línguas por parte dos países envolvidos.

Somos da opinião que um conhecimento mais profundo destas dinâmicas poderá contribuir para uma paulatina tomada de consciência sobre as possibilidades que se abrem a estas literaturas. Uma vez sensibilizados para estas questões tanto académicos como decisores, restar-nos-á aprender a explorar as estradas que se encontram à disposição: se a literatura de língua portuguesa tem mais facilmente acesso aos mecanismos no circuito de circulação restrita, há que discernir como melhor tirar partido deles; e essa mediação será tanto mais eficaz quanto melhor conhecermos o interlocutor.

Neste contexto, a academia tem, ou pode ter, um papel fundamental: tanto a montante, na concepção e gestão dos programas que formam os futuros especialistas em línguas e literaturas; quanto, também a jusante, no diálogo com os agentes de mercado. Afinal de contas, especificamente no caso do livro, o sucesso comercial depende não só mas também de um capital cultural que nem sempre ou nem todos os agentes da indústria cultural estão preparados para reconhecer.

Se o que dizemos se aplica às literaturas de língua portuguesa, e às dinâmicas da sua circulação internacional, não deixa de se ajustar também à realidade das literaturas que, no âmbito da língua portuguesa, têm uma posição menos central: a carreira internacional de Paulina Chiziane é um exemplo paradigmático deste tipo de processo. Por vezes, os agentes da internacionalização vão à procura justamente das franjas, do menos central, do produto de nicho. Este é um comportamento, é certo, que pode redundar numa indesejável 
Cadernos de Literatura Comparada

O português lá fora: algumas reflexões

exoticização do outro. Mas que pode, também - com algum optimismo - ser visto como um momento dialéctico necessário a uma ulterior síntese.

\section{NOTAS}

* Marisa Mourinha é licenciada em Filosofia pela Universidade de Lisboa e pós-graduada em Literatura Comparada pela mesma Universidade. Foi admitida no PEC em 2014/2015 e no PhD-COMP em 2017/2018, como bolseira de doutoramento (PD/ BD/135207/2017), com um projecto de investigação sobre as traduções de António Lobo Antunes para inglês e italiano. É membro em formação do Centro de Estudos Comparatistas, integrando a equipa do Projecto MOV. As suas principais áreas de interesse são estudos de tradução, poesia contemporânea e cinema. Principais publicações: Ariadne Nunes, Joana Moura e Marta Pacheco Pinto (org.) 2020, "Mapping Context through Epitext - Gregory Rabassa's writings and his translations of Lobo Antunes' works." Genetic Translation Studies. Conflict and Collaboration in Liminal Spaces. London: Bloomsbury. Lupetti, Monica e Tocco, Valeria (org.) 2016, "O (im)possível regresso: As Naus de Lobo Antunes e O Retorno de Dulce Maria Cardoso." Giochi di specchi. Modelli, tradizioni, contaminazioni e dinamiche interculturali nei e tra i paesi di lingua portoghese. Pisa: ETS.

${ }^{1}$ Este artigo foi produzido no âmbito de um projecto de doutoramento, com a bolsa FCT PD/BD/135207/2017.

2 “(...) nel 1996, Einaudi mi fece ritradurre Jorge Amado, perché le prime traduzioni italiane lo avevano massacrato. Quando era stato tradotto e pubblicato per la prima volta in Italia, mancavano traduttori dal portoghese brasiliano, per questo era stato affidato a traduttori di lingua spagnola o, tutto al più, portoghese, che comunque ignoravano la realtà e il linguaggio, usi e costumi del nord del Brasile. Un vero disastro. Lo stile dei primi libri, Sudore, Cacao, Jubiabá, povero, secco e asciutto come quelle terre, era diventato pomposo, ricco, pletorico. Per non parlare degli errori, da cui ho creato un bestiario". (Zornetta 2016: 419) ${ }^{3}$ Exemplo paradigmático é o do italiano Umberto Eco, em cujos romances ecoa a sua substancial erudição, que se tornou um autor best-seller como romancista. Este sucesso no campo da ficção acabou por influenciar as vendas das suas obras no domínio do ensaio. Talvez menos comum é o caso do português António Lobo Antunes, que começou como um sucesso comercial, para depois ir ganhando paulatinamente a crítica, atingindo uma consagração de proporções notáveis.

${ }_{4}$ Um exemplo recente é o do sucedido com a editora espanhola de Louise Glück: de acordo com o periódico El Confidencial, 48 horas após o anúncio do prémio Nobel, Andrew Wylie, o agente de Glück, tentava vender a outra editora os direitos de tradução para Espanha, sem sequer avisar aquela que tinha sido, até então, a editora da autora naquele país; assim nos relata Manuel Borrás, o editor da pequena chancela Pre-Textos, especializada em autores de grande risco comercial, que se queixava não só de perder contratos futuros, como de não poder sequer beneficiar das vendas das sete traduções de Glück que haviam publicado nos últimos sete anos (e que, até à atribuição do Nobel, não deram senão prejuízo), visto que a perda dos direitos de tradução os obriga a destruir as cópias em armazém (Cf. Corroto 2020).

${ }^{5}$ É publicada em 2020 com o título Memorie Postume di Brás Cubas, a tradução de Daniele Petruccioli para a editora Fazi.

${ }^{6}$ As Memórias Póstumas de Brás Cubas constituem um caso peculiar no mundo de língua inglesa: teve uma primeira tradução, de William Grossman em 1952, com o título Epitaph of a Small Winner, que foi republicada várias vezes; saiu depois em 1997 
The Posthumous Memoirs of Brás Cubas numa tradução de Gregory Rabassa; e em 2020 são publicadas as traduções de Flora Thomson-DeVeaux pela Penguin Classics, e a de Margaret Jull Costa e Robin Patterson pela chancela Liveright.

${ }^{7}$ Editora com a qual colaboramos desde 2010.

${ }^{8}$ Na formulação actual, desde 2012, tem a designação de Camões - Instituto da Cooperação e da Língua, I. P., e resulta de uma fusão do Instituito Camões com outro órgão do Ministério dos Negócios Estrangeiros, o Instituto Português de Apoio ao Desenvolvimento. Enquanto organismo responsável pela política de língua, é o herdeiro do ICAP - Instituto de Cultura Portuguesa, criado em 1976.

${ }^{9}$ O programa de apoio à tradução do Instituto Português do Livro e das Bibliotecas foi instituído em 1993, mas, de acordo com Jorge Martins, director do Instituto em 2006, "O ano de viragem foi 1997 quando começaram a duplicar os pedidos de apoio às traduções. Tratou-se de um fenómeno associado à presença de Portugal enquanto país-tema da Feira de Frankfurt. A atribuição do Prémio Nobel ao escritor José Saramago, em 1998, foi fulcral e tudo saiu reforçado em 2000, com o convite especial a Portugal para o Salão do Livro em Paris" (Figueiredo 2006).

\section{Bibliografia}

Bassnett, Susan/ André Lefevere (orgs.) (1990), Translation, History and Culture, London, Pinter. Benjamin, Walter (1969), "The Task of the Translator", in Illuminations, New York, Schocken Books, pp. 69-82, [1923].

Bourdieu, Pierre (1992), Les règles de l'art: genèse et structure du champ littéraire, Paris, Seuil. - - (2000), Les structures sociales de l'économie, Paris, Seuil.

Bucaioni, Marco (2017), "Paulina Chiziane e la Ballata d'amore al vento", in Ballata d'amore al vento, Perugia, Edizioni dell'Urogallo, pp. 149-158.

-- (2020), "Quem constrói o cânone internacional das Literaturas Africanas em português? Tradução, instituições e assimetrias Norte/Sul", Mulemba, Rio de Janeiro: UFRJ, Volume 12, Número 22, pp. 28-48.

Casanova, Pascale (2004), The World Republic of Letters, Cambridge (MA), Harvard University Press.

Corroto, Paula (2020) "El editor que tocó el cielo del Nobel y ahora debe destruir todos los libros", El Confidencial, 18/11/2020. <https://www.elconfidencial.com/cultura/2020-11-18/ gluck-premio-nobel-pre-textos_2838379/?utm_campaign=ECDiarioManual\&utm_ medium =social\&utm_source $=$ facebook\&fbclid $=$ IwAR3gu7cymBSjptr4V7zH8y73-raoYQVqfQIXNm-Q-P_heszh6Ai-DWYLC8U> (último acesso em 20/11/2020)

Derrida, Jacques (1985), "Des Tours de Babel", in Difference in Translation, Ithaca \& London, Cornell University Press, pp. 165-248. 
Cadernos de Literatura Comparada

O português lá fora: algumas reflexões

Even-Zohar, Itamar (1990), "The Position of Translated Literature Within the Literary Polysystem", in Polysystem Studies [= Poetics Today 11:1], pp. 45-51. [Revised version of Even-Zohar 1978].

Figueiredo, Leonor (2006), "Tradutores de português são 'janela' para o mundo", Diário de Notícias, 7/10/2006. <https://www.dn.pt/arquivo/2006/tradutores-de-portugues-sao-janela-para-o-mundo-647071.html> (último acesso em 20/12/2020).

Guerini, Andréia/ Marie-Hélène C. Torres/ Walter Carlos Costa (orgs.) (2008), Literatura Traduzida e Literatura Nacional, Rio de Janeiro, 7Letras.

Helgesson, Stefan/ Pieter Vermeulen (orgs.) (2016), Institutions of World Literature: Writing, Translation, Markets, New York, Routledge.

Heilbron, Johan (1999), "Towards a sociology of translation. Book translations as a cultural world system", European Journal of Social Theory 2, 1999: pp. 429-444.

-- (2010), "Structure and Dynamics of the World System of Translation", paper presented at the UNESCO International Symposium Translation and Cultural Mediation. Paris, February 22-23, 2010. <https://ddd.uab.cat/pub/1611/1611_a2015n9/1611_a2015n9a//Heilbron. pdf $>$ (último acesso em 20/11/2020).

Hermans, Theo (1985), The Manipulation of Literature: Studies in Literary Translation, London, Croom Helm.

Holmes, James S. (2000), "The Name and Nature of Translation Studies", in The Translation Studies Reader, London/New York, Routledge, pp. 172-185.

Lambert, José / van Gorp, Hendrik (1985), "On describing translations", in The Manipulation of Literature, London, Croom Helm, pp. 42-53.

Landers, Clifford E. (2001), Literary Translation: A Practical Guide, Clevedon, Multilingual Matters.

Lefevere, André (1992), Translation, Rewriting, and the Manipulation of Literary Fame, London and New York, Routledge.

Mourinha, Marisa (2020), "Mapping Context through Epitext - Gregory Rabassa's writings and his translations of Lobo Antunes' works", in Genetic Translation Studies. Conflict and Collaboration in Liminal Spaces, London: Bloomsbury.

Mulinacci, Roberto (2015), "Apontamentos para uma geopolítica da tradução no século XXI", Cadernos de Tradução, 35, Florianópolis.

Rabassa, Gregory (1975), "If This Be Treason: Translation and its Possibilities", The American Scholar, Vol. 44, n $\mathrm{n}^{\mathrm{1}}$ (Winter 1974-75), pp. 29-39.

-- (2005), If This Be Treason: Translation and Its Dyscontents, A Memoir, New York, New Directions Publishing.

Ricoeur, Paul (1981), Hermeneutics and the Human Sciences, Cambridge \& Paris, Cambridge University Press and Editions de la Maison des Sciences de l'Homme.

Ricci, Rachele (2020), "La diffusione della cultura lusofona nel panorama editoriale italiano: Edizioni dell'Urogallo, La Nuova Frontiera, Tuga Edizioni, Vittoria Iguazú Editora, Voland Edizioni". Diacritica. Anno VI, fasc. 2 (32), 25 aprile 2020. 
Russo, Maria Grazia (2007), "Note traduttologiche queirosiane”, in Tra centro e periferia. Intorno alla lingua portoghese: problemi di diffusione e traduzione, Viterbo, Sette Città, pp. 127154 .

Sapiro, Gisèle (2008), "Translation and the field of publishing: a commentary on Pierre Bourdieu's 'A conservative revolution in publishing'", Translation Studies, 1(2), pp. 154166.

-- (2014), "Translation as a Weapon in the Struggle against Cultural Hegemony in the Era of Globalization", Bibliodiversity - Translation and Globalization, / February 2014.

-- (2016), "How Do Literary Works Cross Borders (or Not)? A Sociological Approach to World Literature", Journal of World Literature 1 (2016), pp. 81-96.

Schleiermacher, Friedrich ([1813] 2012), "On the different methods of translating", in The Translation Studies Reader, London, Routledge, pp.43-63.

Tocco, Valeria / Monica Lupetti (orgs.) (2010), A Língua em Mil Pedaços Repartida. Sulla divulgazione della letteratura lusofona in Italia, Pisa, ETS.

Toury, Gideon (1995), Descriptive Translation Studies and Beyond, Amsterdam/Philadephia, John Benjamins.

Venuti, Lawrence (1995), The Translator's Invisibility. A History of Translation, London and New York, Routledge.

-- (1998), The Scandals of Translation. Towards an Ethic of Difference, London and New York, Routledge.

West III, James L. W. (2012), "The Divergent Paths of British and American Publishing", The Sewanee Review, Vol. 120, No. 4 (Fall 2012), pp. 503-513.

Wilczek, Piotr (2012), "The Literary Canon and Translation: Polish Culture as a Case Study", The Sarmatian Review, Vol. 3 (2012), pp. 1687-1692.

Zornetta, Katia (2016), "Intervista a Daniela Ferioli", Cadernos de Tradução, Florianópolis, v. 36, $\mathrm{n}^{\mathrm{o}}$ 3, pp. 417-426, set.-dez. 2016. 